\title{
Single-Switch ZVZCS Quasi-Resonant CLL Isolated DC-DC Converter for 32" LCD TV
}

\author{
Seung-Hee Ryu*, Jung-Hoon Ahn*, Kwang-Seung Cho* and Byoung-Kuk Lee ${ }^{\dagger}$
}

\begin{abstract}
In this paper, a single-switch ZVZCS quasi-resonant CLL isolated DC-DC converter for driving a low-power (less than $100 \mathrm{~W}$ ) 32" LED backlighting liquid crystal display television (LCD TV) is proposed. The proposed converter exhibits both forward and flyback operational characteristics. All semiconductors are activated and deactivated under the soft switching conditions during the switching transition without additional active devices. The switching frequency varies less than about $10 \mathrm{kHz}$ for load variations, leading to minimizing the efficiency reduction under light load. Furthermore, the low di/dt and dv/dt by soft switching enhance the electromagnetic interference (EMI) performance above $1 \mathrm{MHz}$. A theoretical analysis is described in detail, and a 72-W prototype converter verifies the validity of the analysis.
\end{abstract}

Keywords: LED backlighting LCD TV, Isolated dc-dc converter, Single-switch quasi-resonant, Zero-voltage and zero-current switching (ZVZCS)

\section{Introduction}

Along with the fast growth in the display market with recent digital multimedia broadcasting (DMB) age, power engineers have been studying on efficient power driving methods for the backlight unit (BLU) of LCD TV. In respect of power electronics, especially, compact and costeffective topologies and the accompanying EMI reduction are strongly required for low-power supplies of less than $100 \mathrm{~W}$ for the low and middle-priced TV market $[1,2]$. A flyback converter has been generally applied to the switched-mode power supply (SMPS) for 75-W TVs. However, the flyback converter needs a snubber circuit to suppress high voltage stress across the switch caused by the leakage inductance of the transformer. Besides, high $\mathrm{di} / \mathrm{dt}$ and $\mathrm{dv} / \mathrm{dt}$ by the hard switching result in increasing costs to solve EMI problems, and increased switching losses lead to reduced overall efficiency and limited operation of the converters at high frequency. In order to avoid these drawbacks, soft-switching techniques can be considered as an effective solution. These techniques are classified into two types of topologies: constant switching frequency and variable frequency converters [3-15]. However, the converters with constant frequency employ extra components for the soft switching that cause complex control and cost increases [3-8]. Some variable frequency converters have been proposed. The LLC- or SRC-typed resonant converter enables switches to use ZVS operation and promote system efficiency [9-13]. However, these

$\dagger \quad$ Corresponding Author: College of Information and Communication Engineering, Sungkyunkwan University, Korea. (bkleeskku@skku.edu)

* College of Information and Communication Engineering, Sungkyunkwan University, Korea. (sh.ryu@skku.edu)

Received: December 5, 2014; Accepted: March 29, 2015 converters employ switches more than two for bridge configurations, which is more appropriate for TV applications at more than $150 \mathrm{~W}$. Alternatively, the quasiresonant converters with only a single switch can be valid topologies [14, 15]. However, the main switch in one approach does not guarantee the soft switching, and the free-wheeling diode in the secondary side is hard switched at turn-on [14]. Moreover, the variation of the switching frequency is more than about $200 \mathrm{kHz}$ for load changes. On the other hand, in another approach [15], the main switch and the rectifying diode are stressed by the resonant current during the turn-on time.

In this paper, a single-switch ZVZCS quasi-resonant CLL isolated DC-DC converter applicable for low-power applications is proposed. The operation at the switch turnon is identical to the forward converter. Even though the switch is turned off, the stored energy of the resonant inductor in the primary side is transferred to the load during a certain period. Therefore, this converter has the operational characteristics of both forward and flyback converters without the output filter inductor. In addition, all of semiconductors in the converter are soft switched at turn-on and turn-off as well as the switching frequency of the proposed converter slightly varies for loads unlike the conventional variable frequency converters. Consequently, the efficiency reduction under light load is minimized. For conducted emissions higher than $1 \mathrm{MHz}$, the proposed converter shows considerable advantages compared with the conventional flyback converter.

In Section II, four operating modes about the proposed converter are explained, and the detailed characteristic analysis and control strategy are described. To verify the theoretical analysis, the experimental results are presented in Section III. The conclusion is provided in Section IV. 


\section{Proposed Converter}

\subsection{Description of the Operation Modes}

Fig. 1 shows the circuit model of the proposed converter. It consists of a single-switch $S W$, a resonant capacitor $C_{\mathrm{r}}$ and inductor $L_{\mathrm{r}}$, a rectifying diode $D$, and a transformer, which has a magnetizing inductance $L_{\mathrm{m}}$ and a turn ratio of $n: 1$. To simplify the analysis, it is assumed that:

- All components are ideal and the converter is operating in steady state.

- The input voltage $V_{\text {in }}$ and the output voltage $V_{\mathrm{o}}$ are constant during the switching period because the capacitor is sufficiently large.

- The leakage inductance of the transformer is neglected.

The steady-state operation includes four modes in one switching period $T_{\mathrm{S}}$. The operating modes and waveforms are shown in Figs. 2 and 3, respectively.

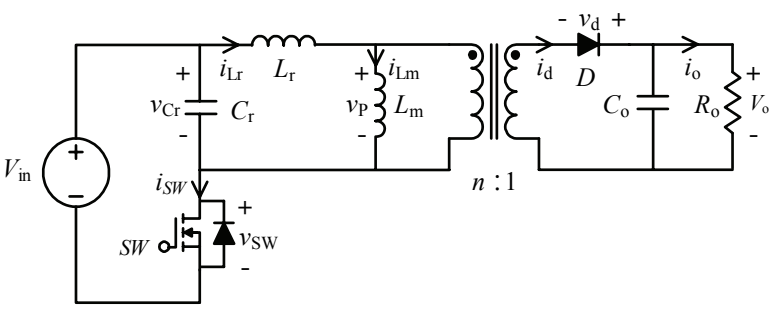

Fig. 1. Circuit model of the proposed converter
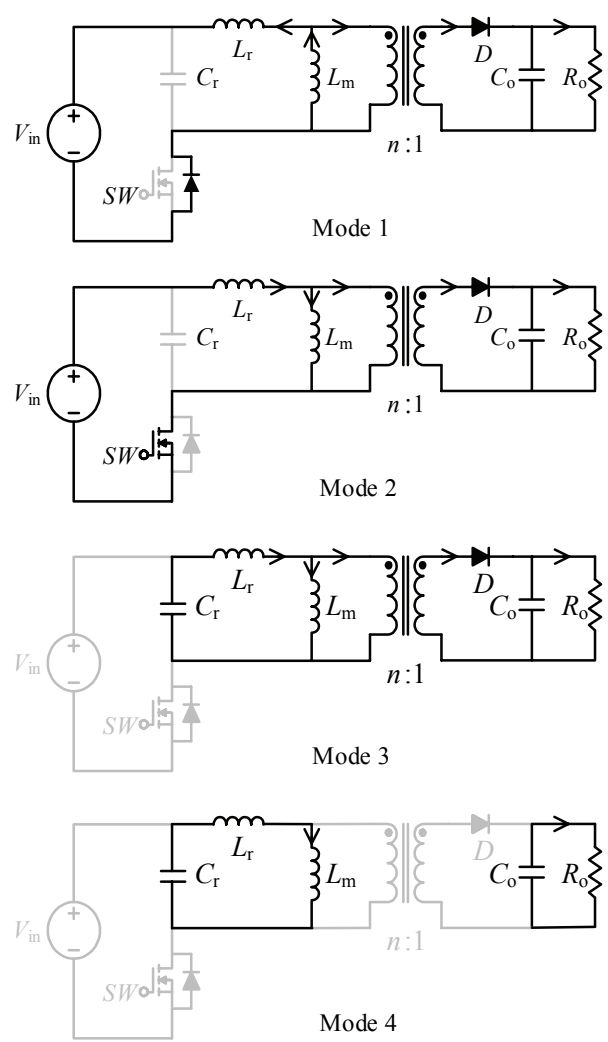

Fig. 2. Operating modes of the proposed converter
1) Mode $1\left[t_{0}, t_{1}\right]$ : At $t_{4}$, when the capacitor voltage $v_{\mathrm{Cr}}$ reaches the input voltage $V_{\text {in }}$ and the switch voltage $v_{\mathrm{SW}}$ becomes zero, the anti-parallel diode of the switch begins to conduct. During this interval, the switch can achieve the ZVS, so that its turn-on switching loss is eliminated. Also, the rectifying diode can turn on under zero-currentswitching (ZCS) conditions, because its current $i_{\mathrm{d}}$ increases from zero.

2) Mode $2\left[\boldsymbol{t}_{1}, \boldsymbol{t}_{2}\right]$ : Prior to $t_{1}$, the main switch $S W$ is turned on. The current through the resonant inductor $L_{\mathrm{r}}$ and the magnetizing inductance $L_{\mathrm{m}}$ linearly increase from zero until $t_{2}$, because the voltages across the resonant capacitor $C_{\mathrm{r}}$ and the magnetizing inductance $L_{\mathrm{m}}$ are $V_{\text {in }}$ and $n V_{\mathrm{o}}$, respectively. The converter transfers the input power to the load through the transformer like a forward converter. The switch current $i_{\mathrm{SW}}$ is the same as the resonant inductor current $i_{\mathrm{Lr}}$. During this mode, the resonant inductor current $i_{\mathrm{Lr}}$ and the magnetizing current $i_{\mathrm{Lm}}$ are represented as follows:

$$
\begin{gathered}
i_{\mathrm{Lr}}(t)=i_{\mathrm{SW}}(t)=\frac{V_{\text {in }}-n V_{\mathrm{o}}}{L_{\mathrm{r}}}\left(t-t_{0}\right)+i_{\mathrm{Lr}}\left(t_{0}\right) \\
i_{\mathrm{Lm}}(t)=\frac{n V_{\mathrm{o}}}{L_{\mathrm{m}}}\left(t-t_{0}\right)+i_{\mathrm{Lm}}\left(t_{0}\right)
\end{gathered}
$$

where $n V_{\mathrm{o}}$ is the output voltage reflected to the primary side of the transformer.

3) Mode $3\left[\boldsymbol{t}_{2}, \boldsymbol{t}_{\mathbf{3}}\right]$ : After the switch $S W$ is turned off at $t_{2}$, the inductor $L_{\mathrm{r}}$ commences resonance with the resonant capacitor $C_{\mathrm{r}}$. The switch voltage $v_{\mathrm{SW}}$ increases smoothly by the resonance, leading it to be turned off under ZVS. Even though the switch was turned off, the stored energy in the resonant inductor $L_{\mathrm{r}}$ is transferred to the load like a flyback

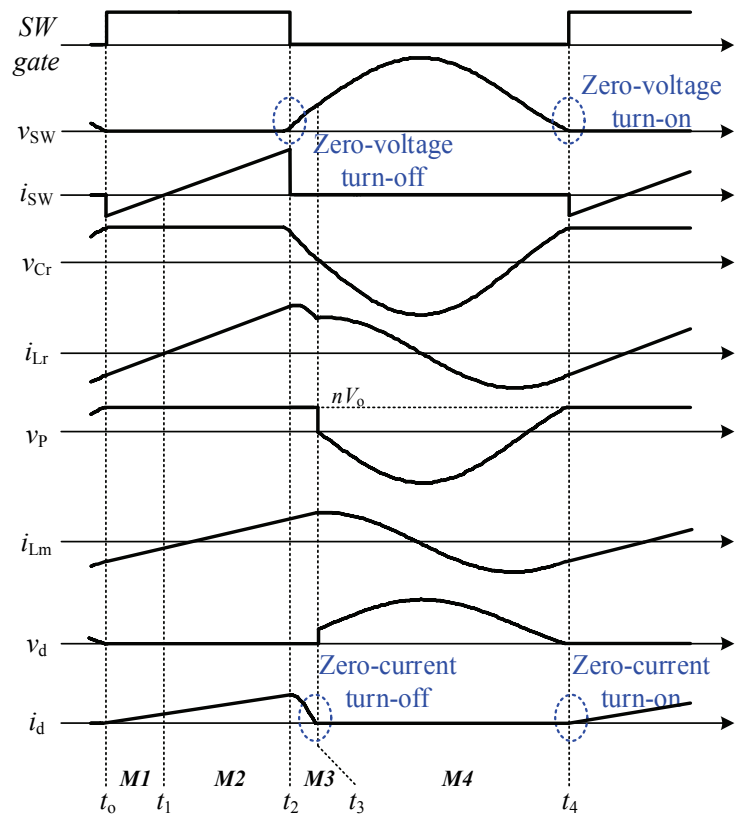

Fig. 3. Operating waveforms of the proposed converter 
converter. The voltage across the magnetizing inductance $L_{\mathrm{m}}$ is clamped to $n V_{\mathrm{o}}$ so that the magnetizing current $i_{\mathrm{Lm}}$ still flows linearly, as shown in Fig. 3. During this mode, the resonant current $i_{\mathrm{Lr}}$, the magnetizing current $i_{\mathrm{Lm}}$, and the resonant capacitor voltage $v_{\mathrm{Cr}}$ are obtained as follows:

$$
\begin{aligned}
i_{\mathrm{Lr}}(t)= & i_{\mathrm{Lr}}\left(t_{2}\right) \cos \omega_{\mathrm{o} 1}\left(t-t_{2}\right)+\frac{V_{\mathrm{in}}-n V_{\mathrm{o}}}{Z_{\mathrm{o} 1}} \sin \omega_{\mathrm{o} 1}\left(t-t_{2}\right) \\
i_{\mathrm{Lm}}(t)= & \frac{n V_{\mathrm{o}}}{L_{\mathrm{m}}}\left(t-t_{2}\right)+i_{\mathrm{Lm}}\left(t_{2}\right) \\
v_{\mathrm{Cr}}(t)= & -Z_{\mathrm{o} 1} i_{\mathrm{L} r}\left(t_{2}\right) \sin \omega_{\mathrm{o} 1}\left(t-t_{2}\right) \\
& +\left(V_{\mathrm{in}}-n V_{\mathrm{o}}\right) \cos \omega_{\mathrm{o} 1}\left(t-t_{2}\right)+n V_{\mathrm{o}}
\end{aligned}
$$

where the characteristic impedance $Z_{\mathrm{o} 1}$ and the angular frequency $\omega_{02}$ in this mode are given by:

$$
Z_{\mathrm{o} 1}=\sqrt{\frac{L_{\mathrm{r}}}{C_{\mathrm{r}}}}, \quad \omega_{\mathrm{o} 1}=\frac{1}{\sqrt{L_{\mathrm{r}} C_{\mathrm{r}}}} .
$$

4) Mode $4\left[\boldsymbol{t}_{3}, \boldsymbol{t}_{4}\right]$ : At $t_{3}$, the secondary rectifying diode $D$ finishes conducting under almost ZCS conditions when the resonant current $i_{\mathrm{Lr}}$ coincides with the magnetizing current $i_{\mathrm{Lm}}$. In this mode, the resonant capacitor $C_{\mathrm{r}}$ is charged and discharged through $L_{\mathrm{r}}$ and $L_{\mathrm{m}}$ until its voltage reaches the input voltage $V_{\text {in }}$ at $t_{4}$. The resonant inductor current $i_{\mathrm{Lr}}$ is the same as the magnetizing inductor current $i_{\mathrm{Lm}}$. The resonant current $i_{\mathrm{Lr}}$ and the resonant capacitor voltage $v_{\mathrm{Cr}}$ are shown as follows:

$$
\begin{aligned}
i_{\mathrm{Lr}}(t)= & i_{\mathrm{Lr}}\left(t_{3}\right) \cos \omega_{\mathrm{o} 2}\left(t-t_{3}\right)+\frac{v_{\mathrm{Cr}}\left(t_{3}\right)}{Z_{\mathrm{o} 2}} \sin \omega_{\mathrm{o} 2}\left(t-t_{3}\right) \\
v_{\mathrm{Cr}}(t)= & -Z_{\mathrm{o} 2} i_{\mathrm{Lr}}\left(t_{3}\right) \sin \omega_{\mathrm{o} 2}\left(t-t_{3}\right) \\
& +v_{\mathrm{Cr}}\left(t_{3}\right) \cos \omega_{\mathrm{o} 2}\left(t-t_{3}\right)
\end{aligned}
$$

where the characteristic impedance $Z_{\mathrm{o} 1}$ and the angular frequency $\omega_{02}$ in this mode are given by:

$$
Z_{\mathrm{o} 2}=\sqrt{\frac{L_{\mathrm{r}}+L_{\mathrm{m}}}{C_{\mathrm{r}}}}, \quad \omega_{\mathrm{o} 2}=\frac{1}{\sqrt{\left(L_{\mathrm{r}}+L_{\mathrm{m}}\right) C_{\mathrm{r}}}} .
$$

Although the voltage stresses across the switch and the rectifying diode increase by the resonance between the resonant inductor $L_{\mathrm{r}}$, the resonant capacitor $C_{\mathrm{r}}$, and the magnetizing inductor $L_{\mathrm{m}}$ during mode 4 , the above description of the proposed converter operation shows that the main switch $S W$ and the rectifying diode $D$ are always turned on and turned off under soft-switching conditions, thereby eliminating the switching losses.

\subsection{Analysis of the operation characteristics}

In this section, the operational characteristics of the proposed converter are discussed. Firstly, the input to output voltage gain of the converter is defined, and variables related to the voltage gain are analyzed.

This converter operates as a forward converter during switch turn-on. On the other hand, after switch turn-off, the energy stored in the resonant inductor $L_{\mathrm{r}}$ and capacitor $C_{\mathrm{r}}$ is transferred to the load like a flyback converter until the resonant inductor current $i_{\mathrm{Lr}}$ is the same as the magnetizing inductor current $i_{\mathrm{Lm}}$. Fig. 4 shows current waveforms of each component during the rectifying diode conduction for an arbitrary load. The magnetizing inductor current $i_{\mathrm{Lm}}$ subtracted from the resonant inductor current $i_{\mathrm{Lr}}$ is multiplied by the transformer turns ratio $n$. It consists of the rectifying diode current. The average value of the periodic signal can be solved by dividing the total area by the period. In order to calculate the average current of the rectifying diode, the variable $K$ is introduced. $K$ is defined as the ratio of conduction areas during $t_{\mathrm{ON}}$ and $t_{23}$ for the given circuit parameters and is given by:

$$
K=\frac{A_{23}}{A_{\mathrm{ON}}}
$$

where $t_{\mathrm{ON}}$ is the conduction time during modes 1 and 2, and $t_{23}$ is the conduction time during mode 3 .

In steady-state operation, when the input power begins to transfer to the load after mode 4 , the initial values of the resonant inductor current $i_{\mathrm{Lr}}$ and magnetizing inductor current $i_{\mathrm{Lm}}$ are always identical, and its currents increase linearly. Therefore, by using (1) and (2), the rectifying diode peak current $I_{\mathrm{Dpk}}$ during switch turn-on can be expressed by:

$$
I_{\mathrm{Dpk}}=n\left(\frac{V_{\mathrm{in}}-n V_{\mathrm{o}}}{L_{\mathrm{r}}} t_{\mathrm{ON}}-\frac{n V_{\mathrm{o}}}{L_{\mathrm{m}}} t_{\mathrm{ON}}\right) .
$$

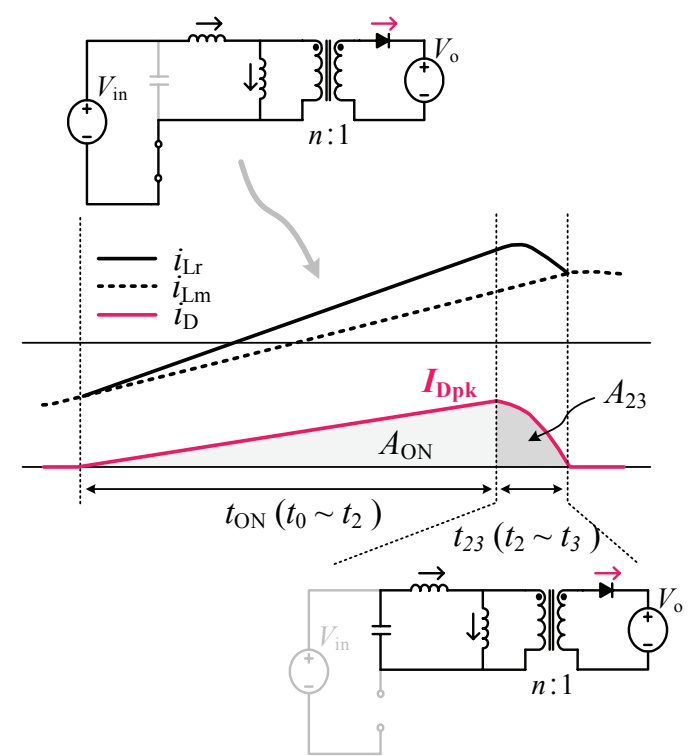

Fig. 4. Key current waveforms during the diode conduction 
From (10) and (11), $A_{\mathrm{ON}}$ and the average current of the rectifying diode $I_{\mathrm{D}}$ are derived as follows:

$$
\begin{aligned}
A_{\mathrm{ON}} & =\frac{1}{2} I_{\mathrm{Dpk}} t_{\mathrm{ON}} \\
I_{D} & =\frac{1}{T_{S}}\left(A_{\mathrm{ON}}+A_{23}\right) \\
& =\frac{n}{2 T_{S}}(1+K)\left[\frac{L_{\mathrm{m}} V_{\mathrm{in}}-\left(L_{\mathrm{r}}+L_{\mathrm{m}}\right) n V_{\mathrm{o}}}{L_{\mathrm{r}} L_{\mathrm{m}}}\right] t_{\mathrm{ON}}^{2} .
\end{aligned}
$$

Eventually, because the average current of the rectifying diode is equal to the output current, the input to output voltage gain of the proposed converter can be characterized as functions of the quality factor $Q$, normalized frequency $f_{\mathrm{n}}$, inductance ratio $\lambda$, transformer turns ratio $n$, and duty ratio $D\left(=t_{\mathrm{ON}} / T_{\mathrm{S}}\right)$ :

$$
\frac{V_{\mathrm{o}}}{V_{\text {in }}}=\frac{1}{n\left[(\lambda+1)+\frac{Q f_{n}(\lambda / \lambda+1)}{\pi(1+K) D^{2}}\right]}
$$

where, $Q=\frac{\omega_{\mathrm{o} 2} L_{\mathrm{m}}}{n^{2} R_{\mathrm{o}}}, \quad f_{\mathrm{n}}=\frac{f_{\mathrm{SW}}}{f_{\mathrm{o} 2}}, \quad \lambda=\frac{L_{\mathrm{r}}}{L_{\mathrm{m}}}$.

The proposed converter is able to operate in no-load conditions. When $Q=0$, the voltage gain of the proposed converter is expressed as a function of the transformer turn ratio $\mathrm{n}$ and the inductance ratio $\lambda$ :

$$
\left.\frac{V_{\mathrm{o}}}{V_{\text {in }}}\right|_{Q=0}=\frac{1}{n(\lambda+1)} .
$$

Then, $A_{23}$ should be calculated. In (10), $A_{\mathrm{ON}}$ can be more easily calculated using (11) and (12). On the other hand, in order to calculate $A_{23}$, it is necessary to know the initial values of $i_{\mathrm{Lr}}$ and $i_{\mathrm{Lm}}$ at the beginning of mode 3 . In modes 1 and 2, the voltage across $L_{\mathrm{m}}$ is clamped to $n V_{\mathrm{o}}$. Therefore, the absolute value of $i_{\mathrm{Lm}}$ at turn-on of the anti-parallel diode of the switch is the same as the value of $i_{\mathrm{Lm}}$ at switch turn-off. Also, because the switch current $i_{\mathrm{SW}}$ flows linearly through the resonant inductor $L_{\mathrm{r}}$ and the magnetizing inductor $L_{\mathrm{m}}$, the initial value of the resonant inductor current $i_{\mathrm{Lr}}$ coincides with the initial value of the magnetizing inductor current $i_{\mathrm{Lm}}$ at $t=t_{0}$. Each initial value of (1), (2), and (4) is defined by:

$$
i_{\mathrm{Lm}}\left(t_{2}\right)=-i_{\mathrm{Lr}}\left(t_{0}\right)=-i_{\mathrm{Lm}}\left(t_{0}\right)=\frac{n V_{\mathrm{o}}}{2 L_{\mathrm{m}}} t_{\mathrm{ON}}
$$

At $t=t_{2}$, the resonant inductor current $i_{\text {Lr }}$ can be derived as (18) by substituting (17) into (1):

$$
i_{\mathrm{Lr}}\left(t_{2}\right)=\frac{2 L_{\mathrm{m}} V_{\mathrm{in}}-\left(2 L_{\mathrm{m}}+L_{\mathrm{r}}\right) n V_{\mathrm{o}}}{2 L_{\mathrm{r}} L_{\mathrm{m}}} t_{\mathrm{ON}}
$$

Therefore, because the energy stored in the resonant capacitor $C_{\mathrm{r}}$ and inductor $L_{\mathrm{r}}$ during $t_{\mathrm{ON}}$ is transferred to the load in mode $3, A_{23}$ can be derived by integrating the rectifying diode current $i_{\mathrm{D}}$ on $t_{23}$ by using (3), (4), (17), and (18):

$$
\begin{aligned}
& A_{23}=n \int_{t_{2}}^{t_{3}}\left[i_{\mathrm{Lr}}(t)-i_{\mathrm{Lm}}(t)\right] d t \\
& =n\left\{\begin{array}{c}
\frac{i_{\mathrm{Lr}}\left(t_{2}\right)}{\omega_{\mathrm{o} 1}} \sin \left(\omega_{\mathrm{o} 1} t_{23}\right)+\frac{V_{i n}-n V_{o}}{\omega_{\mathrm{o} 1} Z_{\mathrm{o} 1}}\left[1-\cos \left(\omega_{\mathrm{o} 1} t_{23}\right)\right] \\
-\frac{n V_{\mathrm{o}}}{2 L_{\mathrm{m}}} t_{23}^{2}-i_{\mathrm{Lm}}\left(t_{2}\right) t_{23}
\end{array}\right\} .
\end{aligned}
$$

$A_{23}$ is a relatively small portion of the total area compared to $A_{\mathrm{ON}}$. In order to facilitate the analysis, a triangle area is considered for estimating $A_{23}$. Eq. (19) can be simplified as:

$$
A_{23} \approx \frac{1}{2} I_{\mathrm{Dpk}} t_{23}
$$

From (12) and (20), the area ratio factor $K$ described earlier is rearranged as

$$
K=\frac{t_{23}}{t_{\mathrm{ON}}}
$$

The average current of the rectifying diode $I_{\mathrm{D}}$ is approximately determined by the values of the resonant inductor current $i_{\mathrm{Lr}}$ and the magnetizing inductor current $i_{\mathrm{Lm}}$ at $t=t_{\mathrm{ON}}$ and the resonant time $t_{23}$ between $C_{\mathrm{r}}$ and $L_{\mathrm{r}}$. In the steady-state operation, the currents $i_{\mathrm{Lr}}$ and $i_{\mathrm{Lm}}$ are always the same at the end of mode 3 . Therefore, the time $t_{23}$ can be calculated through (3), (4), (17), and (18):

$$
t_{23}=\frac{1}{\omega_{\mathrm{o} 1}} \cos ^{-1}\left[\frac{\lambda / 2}{\frac{1}{n V_{\mathrm{o}} / V_{\mathrm{in}}}-(1+\lambda / 2)}\right] \text {. }
$$

In (22), the time $t_{23}$ is constant regardless of loads for the given resonant parameters when the input to output voltage gain is decided.

For a desired voltage gain, it could be necessary to find the relationship between the normalized frequency $f_{\mathrm{n}}$ and the duty ratio $D$ for the given resonant parameters and loads. The proposed converter is able to control the output voltage by changing the duty ratio $D$. In the steady-state operation, $C_{\mathrm{r}}, L_{\mathrm{r}}$ and $L_{\mathrm{m}}$ resonate after switch turn-off, so the turn-off time should be maintained until the voltage 


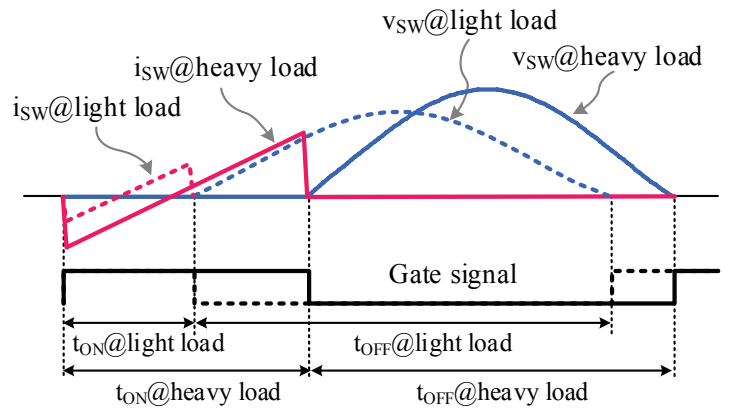

Fig. 5. Variation of $f_{S W}$ and $t_{\mathrm{ON}}$ according to loads

Table 1. Variation trend of the switching frequency and turn-on time

\begin{tabular}{c|c|c}
\hline Load & Turn-on time & Switching frequency \\
\hline Light load & - & + \\
\hline Heavy load & + & - \\
\hline
\end{tabular}

across $C_{\mathrm{r}}$ becomes the input voltage $V_{\text {in }}$ at the end of mode 4. At that time, the switch voltage $v_{\mathrm{SW}}$ is zero. Therefore, when the switch turn-on time for regulating the output voltage $V_{\mathrm{o}}$ is determined, the switching frequency $f_{\mathrm{SW}}$ is determined dependently.

Fig. 5 shows the switching frequency and the switch turn-on time change for load variations with arbitrary resonant parameters. With light load, the switch turn-on time is reduced, so the switch period is reduced. On the other hand, the heavier the load, the larger the switch turnon time. Consequently, the switch period is larger. Table 1 shows the variation trend of the switching frequency and turn-on time while the load changes.

Fig. 6 shows the simulation results on the relationship between the duty ratio $D$ and the normalized frequency $f_{\mathrm{n}}$ while the load varies from $25 \%$ to $133 \%$ under all given circuit conditions as shown in Fig. 6. The higher duty ratio implies the heavy load and the lower duty ratio does the light load. It could be found that an identical pattern between the duty ratio $D$ and the normalized frequency $f_{\mathrm{n}}$ exists regardless of circuit conditions. By using the least squares method (LSM), the normalized frequency $f_{\mathrm{n}}$ has been approximated as a function of the duty ratio $D$ :

$$
f_{\mathrm{n}} \approx-1.3184 D_{2}+0.2515 D+0.9834 \text {. }
$$

The switch of the proposed converter is stressed by the voltage charged in the resonant capacitor $C_{\mathrm{r}}$ through the resonance between $C_{\mathrm{r}}, L_{\mathrm{r}}$, and $L_{\mathrm{m}}$ during switch turn-off. The resonant capacitor voltage $v_{\mathrm{Cr}}$ can be solved by calculating the maximum resonant current $I_{\mathrm{Crmax}}$. At the end of mode 4 , the resonant capacitor voltage $v_{\mathrm{Cr}}$ reaches the input voltage $V_{\text {in }}$ when the maximum resonant current decreases to $\mathrm{i}_{\mathrm{Lr}}\left(t_{0}\right)$.

By the law of energy conservation, the maximum current of the resonant capacitor $C_{\mathrm{r}}$ during mode 4 is given by:

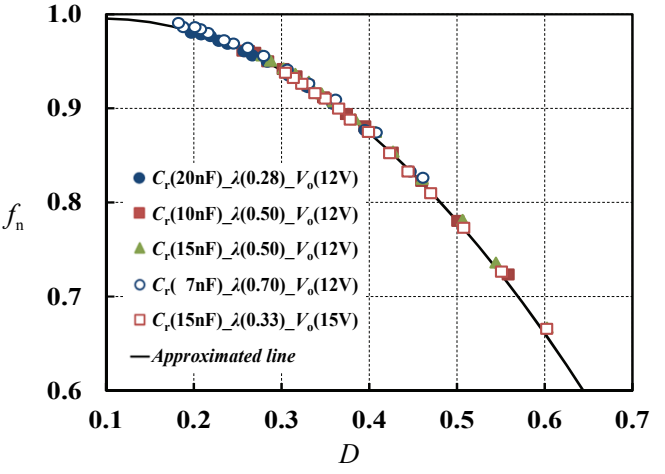

Fig.6. Correlation between $f_{\mathrm{n}}$ and $D$ for different circuit parameters

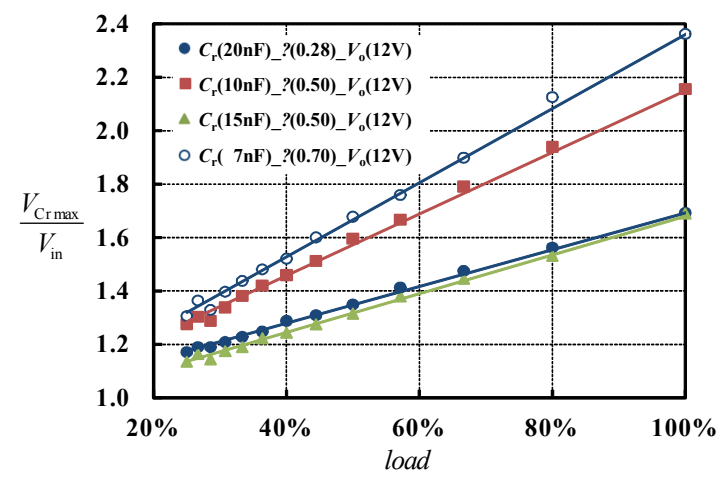

Fig. 7. $V_{\text {Crmax }}$ normalized by $V_{\text {in }}$ according to load variations

$$
I_{\mathrm{Cr} \max }=\sqrt{\left(\frac{V_{\mathrm{in}}}{Z_{\mathrm{o} 2}}\right)^{2}+\left(\frac{n V_{\mathrm{o}}}{2 L_{\mathrm{m}}} t_{\mathrm{ON}}\right)^{2}} .
$$

The maximum capacitor voltage $V_{\text {Crmax }}$ normalized by the input voltage $V_{\text {in }}$ is derived from (24):

$$
\frac{V_{\mathrm{Cr} \max }}{V_{\text {in }}}=\frac{Z_{\mathrm{o} 2} I_{\mathrm{Cr} \max }}{V_{\text {in }}}=\sqrt{1+\left[\frac{n V_{\mathrm{o}}}{V_{\text {in }}} \pi(\lambda+1) \frac{D}{f_{\mathrm{n}}}\right]^{2}} .
$$

Fig. 7 shows the maximum capacitor voltage according to load variations under some circuit conditions. As mentioned earlier, higher load increases the duty ratio $D$, leading to reduction of the normalized frequency $f_{\mathrm{n}}$. Therefore, the larger the load is, the higher the maximum value of the resonant capacitor voltage is. As shown in Fig. 7, the value of the resonant capacitance $C_{\mathrm{r}}$ and/or the value of the magnetizing inductance $L_{\mathrm{m}}$ to reduce the inductance ratio $\lambda$ should be large.

\subsection{Control strategy}

As analyzed in the previous section, the switching frequency of the proposed converter is dependent on the duty ratio. Therefore, the proposed converter requires a PWM controller that can generate a driving pulse with the switching frequency corresponding to the duty ratio 


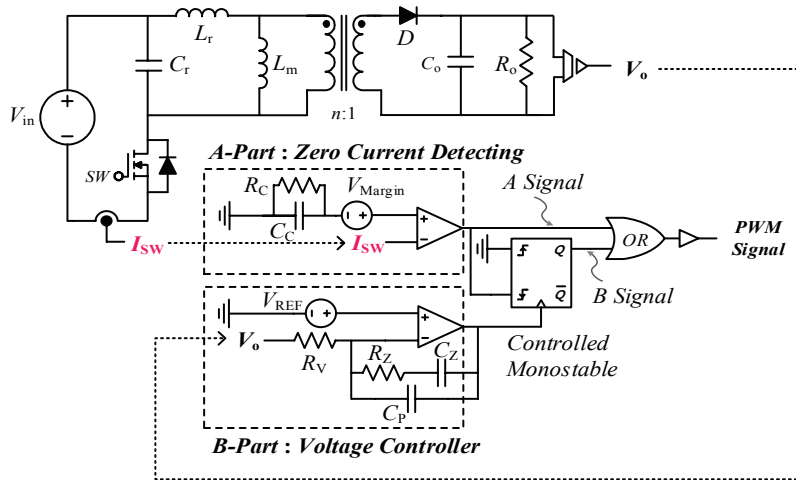

(a)

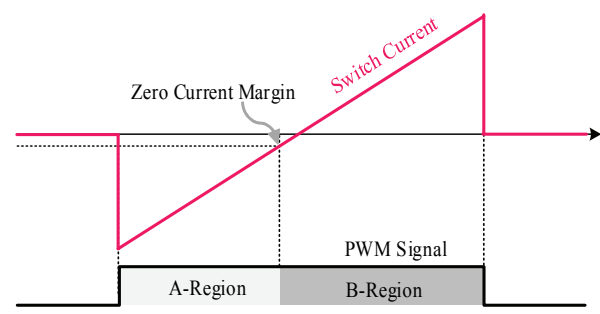

(b)

Fig. 8. Electric diagram with the proposed control strategy: (a) Proposed circuit with control block and (b) PWM strategy

variation in order to regulate the output voltage and satisfy ZVZCS operation for loads.

Fig. 8 shows the electric diagram with the proposed control strategy. In Fig. 8(a), the control block can be divided into three parts. First, the A-Part generates the zero current detecting signal (A signal), which evaluates the zero crossing of the switch current sensed from the shunt resistor. This A signal is used for the switch to be activated in the A-Region shown in Fig. 8(b) for ZVS operation. Second, the B-Part is the voltage controller which determines the conduction time value to keep the switch current flowing for the required output voltage. A type II compensator is used to amplify the difference between the feedback value and reference value. The determined time value is entered into the controlled monostable device. The monostable device is triggered at the falling edge of the A signal and then generates the pulse signal (B signal) corresponding to the conduction time value. Finally, the OR gate outputs the final PWM signal to drive the switch by combining both the A signal and the B signal. By using the proposed control strategy, the switching frequency and turn-on time can be appropriately controlled to regulate the output voltage.

\section{Experimental Results}

\subsection{Operation examination}

In order to verify the theoretical analysis of the proposed converter, the hardware circuit shown in Fig. 1 is
Table 2. Components and parameters for experiment

\begin{tabular}{c|c}
\hline Parameters & Value [Unit] \\
\hline Resonant Capacitance $C_{\mathrm{r}}$ & $20[\mathrm{nF}]$ \\
\hline Resonant Inductance $L_{\mathrm{r}}$ & $57[\mu \mathrm{H}]$ \\
\hline Magnetizing Inductance $L_{\mathrm{m}}$ & $150[\mu \mathrm{H}]$ \\
\hline Output Capacitance $C_{\mathrm{o}}$ & $560[\mu \mathrm{F}]$ \\
\hline Transformer Turns Ratio $n$ & $18: 1$ \\
\hline
\end{tabular}

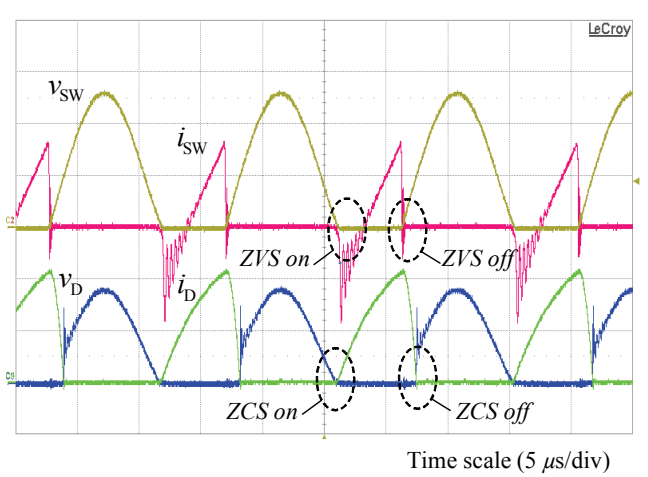

(a)

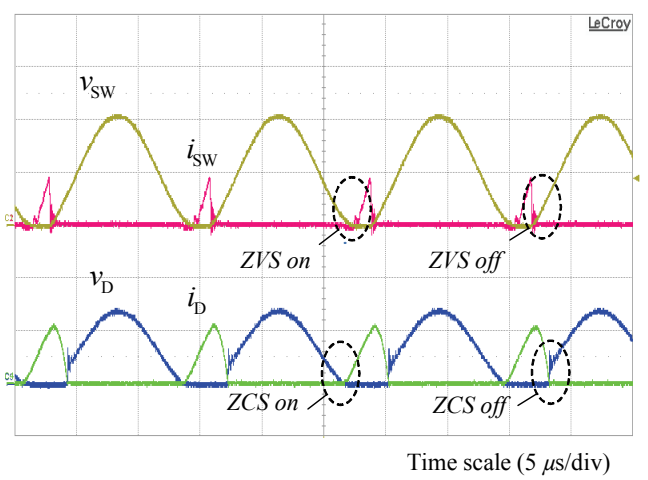

(b)

Fig. 9. Main component waveforms: (a) $100 \%$ load and (b) $30 \%$ load: $v_{\mathrm{SW}}(300 \mathrm{~V} / \mathrm{div}), i_{\mathrm{SW}}(3 \mathrm{~A} / \mathrm{div}), v_{\mathrm{D}}(20$ $\mathrm{V} / \mathrm{div})$, and $i_{\mathrm{D}}(10 \mathrm{~A} / \mathrm{div})$.

implemented. The input voltage, output voltage, and the maximum power are specified as $V_{\text {in }}=310 \mathrm{~V}, V_{\mathrm{o}}=12 \mathrm{~V}$, and $P_{\text {omax }}=72 \mathrm{~W}$, respectively. The main components and parameters of the prototype used for experiments are presented in Table 2.

As shown in section III, the switch is stressed by the voltage charged in the resonant capacitor $C_{\mathrm{r}}$ through the resonance between $C_{\mathrm{r}}, L_{\mathrm{r}}$, and $L_{\mathrm{m}}$ during switch turn-off. The circulating energy should be minimized to reduce the switch voltage stress. An 900-V n-channel MOSFET has been adopted as the switch of the proposed converter. In order to restrict the peak value of the switch voltage less than $900 \mathrm{~V}$, the resonant and magnetizing inductances $L_{\mathrm{r}}$ and $L_{\mathrm{m}}$ are selected with a inductance ratio $\lambda=0.38$. In addition, it is desired that the resonant capacitance $C_{\mathrm{r}}$ be more than $15 n \mathrm{~F}$.

Fig. 9 shows the experimental waveforms of the main components such as the switch voltage $v_{\mathrm{SW}}$, the switch 


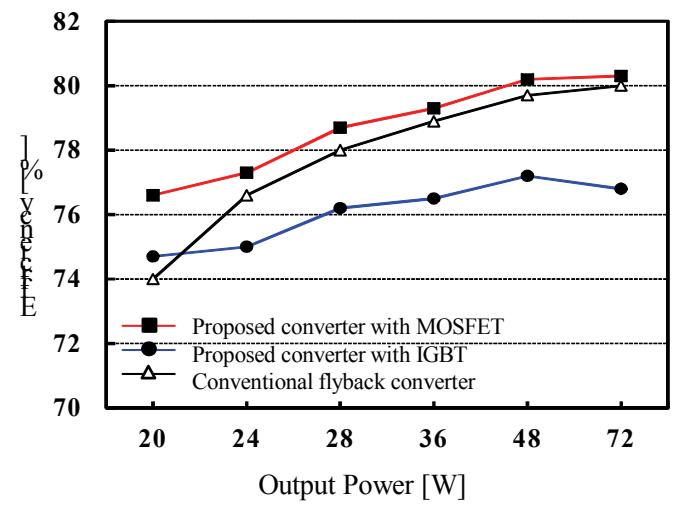

Fig. 10. Efficiency comparison according to switch devices

current $i_{\mathrm{SW}}$, the rectifying diode voltage $v_{\mathrm{D}}$, and the rectifying diode current $i_{\mathrm{D}}$ at $100 \%$ and $30 \%$ loads. All of the active semiconductors of the proposed converter are turned on and turned off under soft-switching conditions. At $100 \%$ load, the switching frequency $f_{\text {SW }}$ is about 69 $\mathrm{kHz}$ for the duty ratio $D=0.4$. At that time, the maximum value of the switch voltage is $834 \mathrm{~V}$. It coincides with the theoretical results $V_{\text {SWmax }}=836 \mathrm{~V}$ obtained from (25) with parameters in Table 2. Fig. 10 shows the efficiency comparison between the conventional flyback converter and the proposed converter. Though the proposed converter is voltage-stressed by the quasi-resonance compared to the flyback converter, the proposed converter achieves soft switching when all semiconductors such as the switch and rectifying diode are turned on and turned off. This implies that the switching losses are reduced, leading to increased system efficiency. As shown in Fig. 10, the efficiency of the proposed converter using an MOSFET as a switch is higher by up to $2 \%$ compared to the conventional converter under light load. It can be shown that the overall efficiency is higher than the flyback converter. However, when an IGBT is adopted as a switch of the proposed converter, the efficiency is reduced. This results from the conduction loss increased by a high saturation voltage when the switch is on. Roughly, it could be estimated that the conduction loss of the IGBT is about 3 times higher than that of the MOSFET from the datasheets. Furthermore, the tail current of the IGBT at turn-off increases the switching loss, leading to deterioration of the system efficiency. It is shown that the MOSFET is the most suitable switching device.

\subsection{Electromagnetic interference examination}

Electromagnetic emission is a critical concern in designing an SMPS for TVs. The conducted emission of the proposed prototype system is compared to the conventional flyback system applied to TVs.

The EMI filter specifications of both systems are identical. A test has been carried out to meet the CISPR Pub. 22 Class B Conducted Emissions Limit. The test results for the proposed converter and the flyback converter

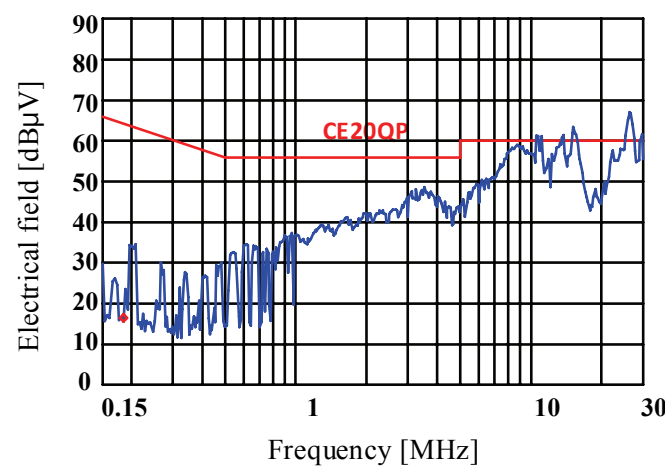

(a)

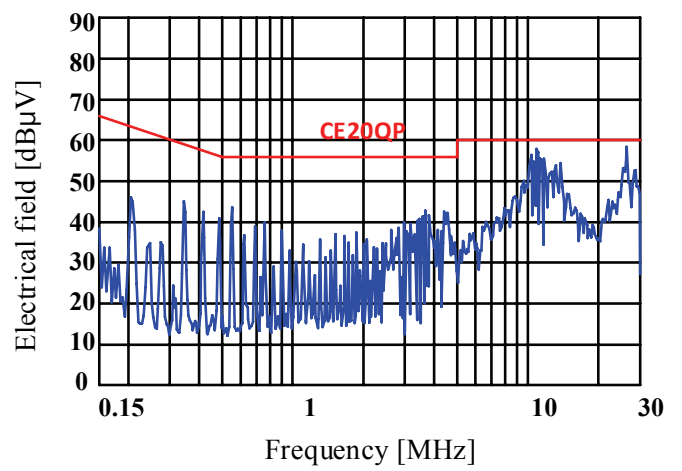

(b)

Fig. 11. CE test results: (a) Flyback converter and (b) Proposed converter.

at the maximum output power $P_{\text {omax }}=72 \mathrm{~W}$ are given in Fig. 11. The emission electrical fields of both systems below 10 $\mathrm{MHz}$ are confirmed to be lower than the standard reference level. However, at the frequency range of 1-30 MHz, the electrical field of the proposed converter system is much lower than that of the conventional flyback converter system. Even though it is known well that the conducted emissions higher than $10 \mathrm{MHz}$ can be relatively solved by slowing down the turn-off speed of the main MOSFET. But for frequency around $1 \mathrm{MHz}$, the proposed converter shows outstanding advantages. The measured quasi-peak levels of the flyback converter system were $58.9 \mathrm{~dB} \mu \mathrm{V}$ at 14.23 $\mathrm{MHz}$ and $61.2 \mathrm{~dB} \mu \mathrm{V}$ at 25.6 MHz. On the other hand, the measured levels of the proposed system were $57.6 \mathrm{~dB} \mu \mathrm{V}$ at $11.74 \mathrm{MHz}$ and $50.1 \mathrm{~dB} \mu \mathrm{V}$ at $27.1 \mathrm{MHz}$. From the results, it can be estimated that the radiated emission performance of the proposed converter will be superior to the conventional flyback converter by the lower $\mathrm{di} / \mathrm{dt}$ and $\mathrm{dv} / \mathrm{dt}$.

\section{Conclusion}

A single-switch ZVZCS quasi-resonant CLL isolated converter for low-power and low-priced electric appliances has been proposed. The proposed converter achieves the soft switching of all semiconductors during switching 
transition. Though the circulating current increases during the switch turn-off, the proposed converter provides the following advantages:

1) Improved efficiency by reducing switching losses through the soft switching of all semiconductors;

2) Low EMI above $1 \mathrm{MHz}$ complying with the CISPR 22 Class B Conducted Emissions limit.

The proposed converter was validated with experimental results by implementing a $72-\mathrm{W}$ prototype converter. The proposed converter shows high efficiencies for loads. The efficiency under light load is higher by more than $2 \%$ compared to the conventional flyback converter.

\section{References}

[1] K. S. Nam and O. K. Kwon, "A highly powerefficient LED backlight driving system for LCD TVs," IEEE Trans. Consum. Electron., vol. 58, no. 2, pp. 264-268, May 2012.

[2] W. Y. Choi, "A highly power-efficient LED backlight power supply for LCD display," J. Display. Technol., vol. 9, no. 5, pp. 382-387, May 2013.

[3] C. M. Wang, "A novel ZCS-PWM flyback converter with a simple ZCS-PWM communication cell," IEEE Trans. Ind. Electron., vol. 55, no. 2, pp.749-757, Feb. 2008.

[4] Y. K. Lo and J. Y. Lin, "Active-clamping ZVS flyback converter employing two transformers," IEEE Trans. Ind. Electron., vol. 22, no. 6, pp. 2416-2423, Nov. 2007

[5] Y. C. Hsieh, M. R. Chen, and H. L. Cheng, "An interleaved flyback converter featured with zerovoltage transition," IEEE Trans. Power Electron., vol. 26, no. 1, pp. 79-84, Jan. 2011.

[6] E. Adib and H. Farzanehfard, "Analysis and design of zero-current switching forward converter with simple auxiliary circuit," IEEE Trans. Power Electron., vol. 27, no. 1, pp. 144-150, Jan. 2012.

[7] J. G. Cho and G. H. Cho, "Single-cycle resonant converter: a new group of quasi-resonant converters suitable for high-performance $\mathrm{dc} / \mathrm{dc}$ and ac/ac conversion application," IEEE Trans. Ind. Electron., vol. 38, no. 4, pp. 260-267, Aug. 1991.

[8] B. R. Lin, C. L. Huang, and J. F. Wan, "Analysis, design, and implementation of a parallel ZVS converter," IEEE Trans. Ind. Electron., vol. 55, no. 4, pp. 1586-1594, Apr. 2008.

[9] C. G. Kim, K. C. Lee, and B. H. Cho, "Analysis of current distribution in driving multiple cold cathode fluorescent lamps (CCFL)," IEEE Trans. Ind. Electron., vol. 54, no. 1, pp. 365-373, Feb. 2007.

[10] S. H. Cho, C. S. Kim, and S. K. Han, "Highefficiency and low-cost tightly regulated dual-output
LLC resonant converter," IEEE Trans. Ind. Electron., vol. 59, no. 7, pp. 2982-2991, Jul. 2012.

[11] B. C. Kim, K. B. Park, and G. W. Moon, "Asymmetric PWM control scheme during hold-up time for LLC resonant converter," IEEE Trans. Ind. Electron., vol. 59, no. 7, pp. 2992-2997, Jul. 2012.

[12] W. Y. Choi, "A highly power-efficient LED backlight power supply for LCD Display," J. Display. Technol., vol. 9, no. 5, pp. 382-387, May 2013.

[13] I. Demirel and B. Erkmen, "A very low-profile dual output LLC resonant converter for LCD/LED TV application," IEEE Trans. Power Electron., vol. 29, no. 7, pp. 3514-3524. Jul. 2014.

[14] J. M. Kwon, W. Y. Choi, and B. H. Kwon, "Singleswitch quasi-resonant converter," IEEE Trans. Ind. Electron., vol. 56, no. 4, pp. 1158-1163, Apr. 2009.

[15] A. Emrani, E. Adib, and H. Farzanehfard, "Singleswitch soft-switched isolated DC-DC converter," IEEE Trans. Power Electron., vol. 27, no. 4, pp. 19521957, Apr. 2012.

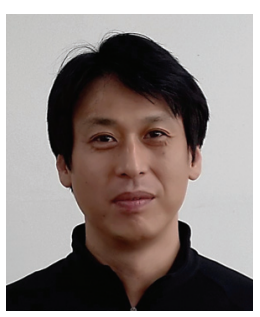

Seung-Hee Ryu He received the M.S. degree from Hanyang Univ., Seoul, Korea, in 2000. From 2000 to 2012, he has been a Senior Researcher at LG Electronics, Korea. Since 2012, he has worked for his Ph. D at Sungkyunkwan Univ., Suwon, Korea. His research interests include resonant inverter for induction heating and inductive power transfer systems.

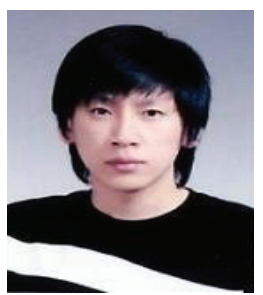

Jung-Hoon Ahn He received the M.S. degree from Sungkyunkwan Univ., Suwon, Korea, in 2013. Since 2013, he has worked for his Ph.D at Sungkyunkwan University. His research interests include battery management system (BMS), DC-DC converter for PHEV/ $\mathrm{EV}$ and advanced motor drive systems.

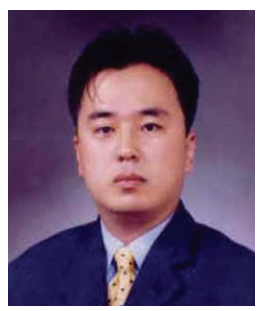

Kwang-Seung Cho $\mathrm{He}$ received the M.S. degree from Dong-A Univ., Busan, Korea, in 2001. Currently, he is a Senior Researcher at Samsung EletroMechanics, Korea. Since 2012, he has worked for his Ph.D at Sungkyunkwan Univ., Suwon, Korea. His research interests include resonant converter for the home appliances and battery charger for HEVs/EVs. 


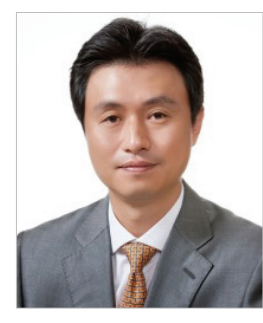

Byoung-Kuk Lee He received the B.S. and the M.S. degrees from Hanyang University, Seoul, Korea, in 1994 and 1996, respectively and the Ph.D. degree from Texas A\&M University, College Station, TX, in 2001, all in electrical engineering. From 2003 to 2005, he has been a Senior Researcher at Power Electronics Group, Korea Electrotechnology Research Institute (KERI), Changwon, Korea. From 2006 Dr. Lee joins at College of Information and Communication Engineering, Sungkyunkwan University, Suwon, Korea. His research interests include on-board charger and wireless power transfer for electric vehicles, energy storage systems, hybrid renewable energy systems, dc distribution systems for home appliances, power conditioning systems for fuel cells and photovoltaic, modeling and simulation, and power electronics. Prof. Lee is a recipient of Outstanding Scientists of the 21st Century from IBC and listed on 2008 Ed. of Who's Who in America. Prof. Lee is an Associate Editor in the IEEE Transactions on Industrial Electronics and Power Electronics. He was the presenter for Professional Education Seminar with the topic of "On-Board Charger Technology for EVs and PHEVs" at IEEE Applied Power Electronics Conference in 2014 and was the General Chair for IEEE Vehicular Power and Propulsion Conference (VPPC) in 2012. 